\title{
O.В. Темная
}

Институт экономики естественных монополий РАНХиГС при Президенте РФ, Москва

\section{Д.В. Агафонов}

Институт экономики естественных монополий РАНХиГС при Президенте РФ, Москва

\section{О.О. Мозговая}

Институт экономики естественных монополий РАНХиГС при Президенте РФ, Москва

\section{Стимулирующее регулирование водоснабжения в условиях ограничения тарифов}

Аннотация. В статье рассмотрены применяемые в Российской Федерации и зарубежных странах методы регулирования тарифов на услуги естественных монополий на примере такой отрасли, как водоснабжение. Выделены три принципа, на которых основывается регулирование тарифов на услуги естественных монополий, - компромиссный, компенсирующий и стимулирующий. Преимущество одного из стимулирующих методов регулирования - метода эталонных затрат - состоит в сокращении трудоемкости процесса регулирования в регулируемых предприятиях. Другое положительное свойство этого метода возможность ранжировать организации по экономической эффективности затрат и стимулировать ее повышение именно для организаций с низкой эффективностью. Сравнительный анализ находящихся в открытом доступе показателей себестоимости водоснабжающих организаций выявил, что затраты на приобретение материальных ресурсов, амортизация и расходы на аренду зависят от специфических условий деятельности организаций, поэтому в качестве результирующей переменной для метода эталонных затрат целесообразно рассмотреть себестоимость, из которой исключены эти виды расходов: безресурсную составляющую себестоимости. Авторы статьи рассчитали функцию аппроксимации безресурсной составляющей себестоимости водоснабжения от трех влияющих факторов и на ее основе произвели расчет эталонной безресурсной составляющей себестоимости методом целевой эффективности, алгоритм которого подробно описан в статье. Несмотря на то что полученная функция аппроксимации нуждается в усовершенствовании, расчеты, проведенные авторами, доказывают возможность определения эталонных затрат для регулирования тарифов на услуги российских предприятий водоснабжения.

Ключевые слова: водоснабжение, естественная монополия, регулирование тарифов, стимулирующее регулирование, бенимаркинг, эталонные затраты, целевая эффективность.

Классификация JEL: L16, L43, L51, L95.

DOI: $10.31737 / 2221-2264-2021-52-4-8$

\section{1. Введение}

Принципы регулирования тарифов, заложенные в законодательство Российской Федерации, не создают должных стимулов повышения эффективности для отечественных коммунальных предприятий. В передовой международной практике для стимулирова- 
ния коммунальных предприятий повышать эффективность активно и достаточно успешно применяется эталонный метод регулирования тарифов. Возможность применения метода сравнения аналогов (эталонных затрат) при регулировании тарифов российских предприятий водоснабжения рассматривается в әтой статье.

\section{1. Обзор литературы}

Проблемы регулирования тарифов науслуги естественных монополий широко обсуждались в российской научной литературе в период реформирования энергетической отрасли и отрасли жилищно-коммунальных услуг.

Экономико-математические модели компромиссных тарифов на жилищно-коммунальные услуги, включая тарифы на водоснабжение, были разработаны последователями созданной профессором В.А. Кардашем школы компромиссного анализа экономики. Авторы предложили применить методику компромиссного ценообразования к социально-рыночным сделкам (Матвиенко и др., 2019). В соответствии с этапами методики ранжируют потребителей (на платежеспособных и неплатежеспособных (частично платежеспособных)) и производителей услуг (на конкурентоспособных и неконкурентоспособных). Далее определяется цена достижения рыночного компромисса между совокупным спросом и совокупным предложением на потребительском рынке (Кракашова, 2010). Исходя из компромиссной цены, рассчитывается объем бюджетных субсидий для удовлетворения социального спроса неплатежеспособных потребителей, что нарушает компромиссное равновесие, которое должно восстанавливаться путем введения в действие бюджетных и налоговых рычагов государственного регулирования.

Установить пороговые значения доли доходов населения, которая расходуется на оплату жилищно-коммунальных услуг, предлагал исполнительный директор Центра по әффективному использованию энергии И.А. Башмаков (Башмаков, 2003). По результатам исследований (Башмаков, 2004) он сделал вывод о том, что общепринятое суждение о неэластичности спроса на коммунальные услуги является неверным: существует «максимум способности и готовности граждан оплачивать ЖКУ», а в случае превышения тарифов сверх этого максимума возрастет не только выручка предприятий, оказывающих услуги ЖКХ, но и задолженность потребителей за оказанные услуги.

Этим рекомендациям соответствуют «Методические указания по расчету предельных индексов изменения размера платы граждан за коммунальные услуги», утвержденные приказом Министерства регионального развития РФ от 23.08.10 № 378, которые содержат критерии доступности для граждан платы за коммунальные услуги и предусматривают расчет оценки доступности совокупного платежа платы населения за потребляемые коммунальные услуги в муниципальном образовании, исходя из предлагаемых тарифов. 
Таким образом, компромиссный принцип при регулировании тарифов естественных монополий базируется на соответствии цены и объема совокупного спроса цене и объему совокупного предложения.

Два других направления регулирования тарифов на услуги естественных монополий - затратный (по затратам и норме доходности Cost-plus regulation), основанный на полной компенсации расходов, и стимулирующего регулирования (Incentive regulation).

Эволюция методов регулирования тарифов подробно описана в (Сорокин, 2015). Автор подробно рассматривает преимущества и недостатки базовых методов регулирования тарифов - затратного и регулирования предельного роста цены (price cap). относит:

К методам стимулирующего регулирования М.А. Сорокин

- контракт с разделенным экономическим эффектом (profit sharing contract, он же механизм скользящей шкалы (sliding scale mechanism));

- регулирование по эталонным показателям, или бенчмаркинг (yardstick regulation, or benchmarking).

В статье (Сорокин, 2015) не упомянут метод доходности инвестированного капитала (метод RAB), который относится к долгосрочным методам регулирования. Необходимая валовая выручка, установленная методом доходности инвестированного капитала, включает в себя средства на возврат инвестированного капитала и доход на инвестированный капитал, что, с одной стороны, гарантирует внешнему инвестору возврат вложенных средств, а с другой стороны, позволяет равномерно по годам распределить инвестиционные затраты в тарифной нагрузке на потребителей (Kenton, 2018).

Контракт с разделенным экономическим эффектом, или метод скользящей шкалы, - это регулирование путем установления целевой нормы доходности инвестиций и диапазона, в границах которого регулируемая организация оставляет все доходы для собственного развития (Mayer, Vickers, 1996). Если доходы превышают границы установленного диапазона, они учитываются в пользу потребителей путем снижения тарифов в будущих периодах. Убытки сверх установленных норм страхует регулирующий орган. Недостатком метода является возможность манипуляций со стороны регулируемых компаний.

Возможность повышения әффективности работы предприятий коммунального водоснабжения на базе формирования квазиконкурентных условий в отрасли посредством организации сравнительной конкуренции между операторами услуг (the competition by comparison или yardstick competition) на основе результатов бенчмаркинговых исследований обоснована в работах С. Берга (Berg, 2010).

Сравнительная оценка экономической әффективности деятельности компаний применяется в тарифном регулировании по эталонным показателям. В работе (Akimov, Simshauser, 2018) представ- 
лена следующая классификация методов тарифного регулирования с использованием эталонных показателей:

1) метод удельных показателей (partial indicators) - эталонные затраты устанавливаются исходя из удельных показателей, например операционные издержки на одно подключение; число подключений на одного работника;

2) комплексные методы эконометрическогоанализа (total methods) устанавливают относительную эффективность каждого предприятия в кластере сходных предприятий. Зависимость между исходными и результирующими параметрами, а также влияющими на них переменными может определяться методами наименьших квадратов (ordinary least squares), стохастического пограничного анализа (stochastic frontier analysis), анализа сверстки данных (data envelopment analysis).

Эталонные затраты могут устанавливаться на граничном или среднем уровнях. Методы, основанные на определении әффективности лучших образцов, используются на начальных этапах применения эталонного регулирования для выравнивания производительности в регулируемой отрасли, после чего появляется возможность для применения усредняющих методов регулирования:

1) инженерный метод (engineering approach) - тарифы рассчитываются для виртуальных предприятий различного масштаба с оптимизированными технологическими и экономическими параметрами;

2) метод бенчмаркинга производственных процессов (process benchmarking) применяется для каждой стадии производственного процесса, он позволяет выявить проблемные участки организации;

3) метод бенчмаркинга на основе опроса потребителей (customer survey benchmarking) имеет низкую объективность, так как у потребителей нет полной информации о деятельности предприятий. Может использоваться как дополнение к результатам сравнительного анализа, выполненного другими методами.

По нашему мнению, инженерный метод, по сути, не является методом бенчмаркинга, так как при разработке эталонных предприятий не используются данные сравнения действующих предприятий. Остальные методы регулирования по эталонным показателям могут быть объединены в группу «Методы регулирования на основе бенчмаркинга».

Метод регулирования тарифов, аналогичный инженерному методу, предложен в (Гембик, Городкова, 2018). Предлагаемый ими метод прототипа состоит в разработке нормативов сырья, материалов, численности сотрудников, ремонтов - по всем статьям затрат компании. Таким образом, предложенный метод прототипа предусматривает не просто эталонную модель предприятия, но и регламентирует размер 
затрат по каждой статье себестоимости, как и метод эталонирования статей затрат (Довлатова, Эпштейн, 2019).

По нашему мнению, регламентация затрат по статьям себестоимости является излишней, так как даст органам государственного регулирования тарифов возможность дополнительно необоснованно снижать затраты регулируемых организаций.

Авторы статьи классифицировали методы регулирования естественных монополий по принципам, заложенным в их основу: компромиссный, компенсирующий и стимулирующий (рис. 1). Действующим законодательством Российской Федерации предусмотрена возможность применения методов расчета тарифов в сфере водоснабжения, приведенных в табл. 1.

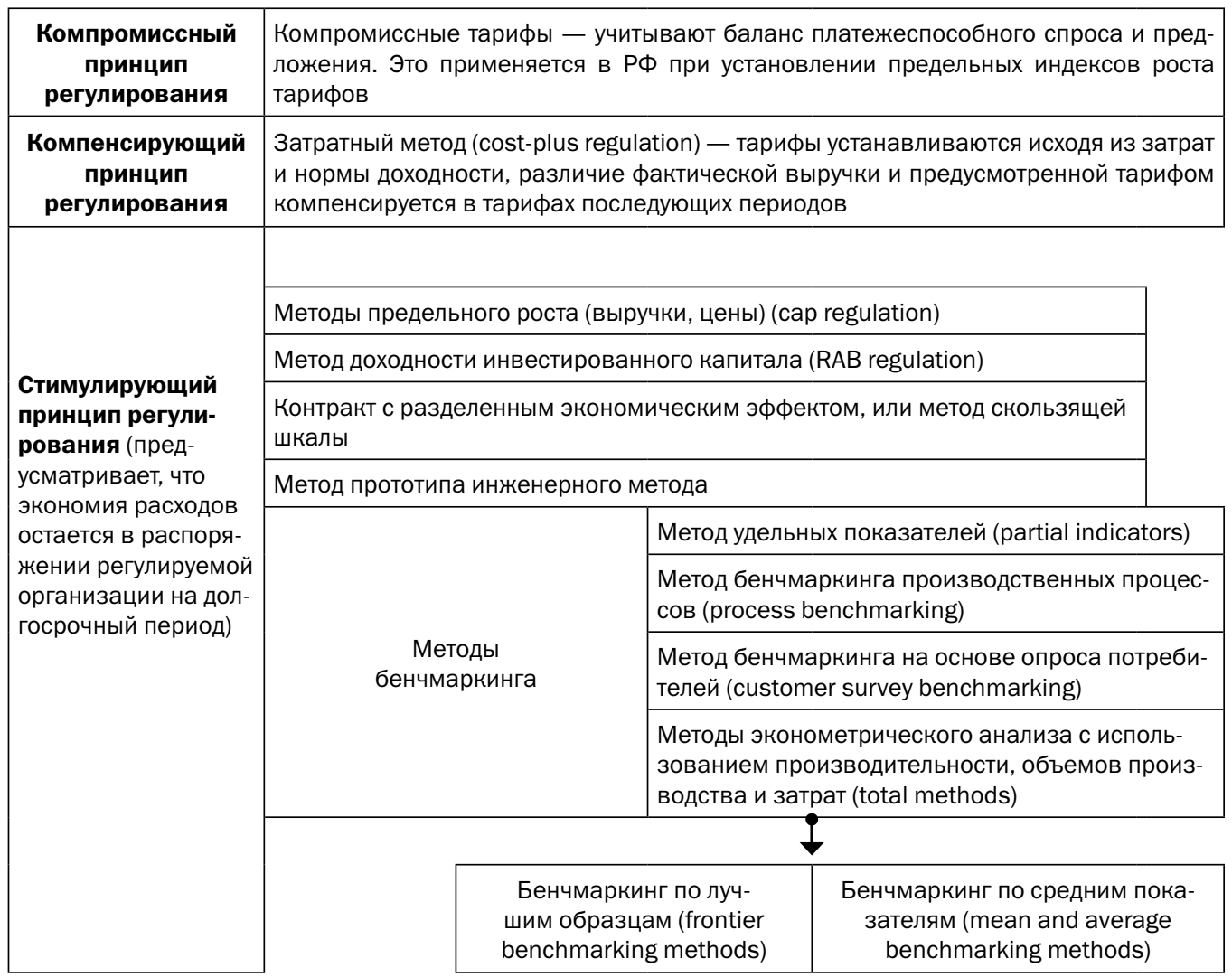

Puc. 1

Классификаиия методов регулирования тарифов по приниипам регулирования

Источник: разработано авторами. 
таблица 1

Критерии выбора метода регулирования тарифов в сфере водоснабжения и водоотведения Российской Федерации

\begin{tabular}{|c|c|c|c|c|}
\hline Показатель & $\begin{array}{c}\text { Метод эконо- } \\
\text { мически обо- } \\
\text { снованных } \\
\text { расходов }\end{array}$ & $\begin{array}{l}\text { Метод сравне- } \\
\text { ния аналогов }\end{array}$ & $\begin{array}{c}\text { Метод } \\
\text { индексации }\end{array}$ & $\begin{array}{l}\text { Метод доходности } \\
\text { инвестированного } \\
\text { капитала }\end{array}$ \\
\hline $\begin{array}{l}\text { Срок действия } \\
\text { тарифов }\end{array}$ & 1 год & $\begin{array}{l}1 \text { год (транс- } \\
\text { портировка } \\
\text { воды до } \\
10 \kappa м / 10 \%)\end{array}$ & $\begin{array}{l}\text { Долгосрочный } \\
\text { период с воз- } \\
\text { можностью еже- } \\
\text { годной коррек- } \\
\text { тировки до } 5 \text { лет }\end{array}$ & $\begin{array}{l}\text { На каждый год долго- } \\
\text { срочного периода регу- } \\
\text { лирования на основе } \\
\text { долгосрочных параметров } \\
\text { регулирования до } 5 \text { лет }\end{array}$ \\
\hline \multirow{7}{*}{$\begin{array}{l}\text { Долгосрочные } \\
\text { параметры } \\
\text { регулирования }\end{array}$} & \multirow{7}{*}{-} & \multirow{7}{*}{-} & \multicolumn{2}{|c|}{ Базовый уровень операционных расходов } \\
\hline & & & \multicolumn{2}{|c|}{$\begin{array}{l}\text { Индекс эффективности операционных } \\
\text { расходов }\end{array}$} \\
\hline & & & \multirow{4}{*}{$\begin{array}{l}\text { Норматив- } \\
\text { ный уровень } \\
\text { прибыли }\end{array}$} & $\begin{array}{l}\text { Норматив чистого оборот- } \\
\text { ного капитала }\end{array}$ \\
\hline & & & & $\begin{array}{l}\text { Норма доходности инве- } \\
\text { стированного капитала }\end{array}$ \\
\hline & & & & $\begin{array}{l}\text { Срок возврата инвестиро- } \\
\text { ванного капитала }\end{array}$ \\
\hline & & & & $\begin{array}{l}\text { Первоначальный раз- } \\
\text { мер инвестированного } \\
\text { капитала }\end{array}$ \\
\hline & & & \multicolumn{2}{|c|}{$\begin{array}{l}\text { Показатели энергосбережения и энергетиче- } \\
\text { ской эффективности }\end{array}$} \\
\hline \multirow{3}{*}{$\begin{array}{l}\text { Стимулы сни- } \\
\text { жения теку- } \\
\text { щих расходов }\end{array}$} & \multirow{3}{*}{-} & \multirow{3}{*}{-} & \multicolumn{2}{|c|}{$\begin{array}{l}\text { Индекс эффективности операционных } \\
\text { расходов. }\end{array}$} \\
\hline & & & \multicolumn{2}{|c|}{$\begin{array}{l}\text { Уменьшение НВВ с учетом невыполнения } \\
\text { показателей энергосбережения и энергети- } \\
\text { ческой эффективности. }\end{array}$} \\
\hline & & & \multicolumn{2}{|c|}{$\begin{array}{l}\text { Сохранение экономии операционных рас- } \\
\text { ходов и затрат на энергоресурсы в течение } \\
\text { пяти лет }\end{array}$} \\
\hline $\begin{array}{l}\text { Источники } \\
\text { инвестиций }\end{array}$ & \multicolumn{3}{|c|}{ Амортизация и прибыль, учитываемые в тарифе } & $\begin{array}{l}\text { Акционерный и заемный } \\
\text { капитал (возврат инве- } \\
\text { стированного капитала } \\
\text { и доход на инвестирован- } \\
\text { ный капитал учитываются } \\
\text { в тарифе в течение } 10-30 \\
\text { лет) }\end{array}$ \\
\hline
\end{tabular}

Источник: Федеральный закон от 07.12.2011 № 416-Ф3 «О водоснабжении и водоотведении» (http://www.consultant.ru/).

Метод сравнения аналогов применяется лишь для установления тарифов на транспортировку холодной воды для организаций, не являющихся гарантирующими, если протяженность их сетей не превышает 10 км. Метод экономически обоснованных расходов применяется 
только для новых организаций, после первого года функционирования организация должна перейти на долгосрочный метод регулирования.

Практически повсеместно в России для установления тарифов на услуги водоснабжения применяется метод индексаиии. Метод доходности инвестированного капитала, который планировалось применять для концессий и проектов в рамках государственно-частного партнерства, применяется редко, так как в условиях жесткого ограничения роста тарифов на услуги коммунального хозяйства невозможно дополнительное увеличение роста тарифа за счет таких составляющих, как возврат инвестированного капитала и доход на инвестированный капитал.

По мнению авторов, фактически в сфере водоснабжения Российской Федерации применяется не просто индексный метод регулирования тарифов, а гибридный. Это обусловлено тем, что темп прироста тарифа для населения законодательно ограничен, а это - компонента компромиссного типа регулирования. В качестве компонентов стимулирующего регулирования при формировании тарифа методом индексации выступают «индекс эффективности операционных расходов», предусматривающий их ежегодное снижение, - показатель водои энергосбережения, так как при невыполнении этих показателей могут быть применены штрафные санкции в виде снижения плановой необходимой валовой выручки (НBВ) на последующие годы.

\section{2. Актуальность исследования}

За период 2010-2019 гг. прослеживается устойчивое сокращение объемов потребления в сфере водо-канализационного хозяйства. Снижение объема воды, отпущенной потребителям за этот период, составило 23,6\%. Если учесть, что тариф на воду рассчитывается как частное от деления плановой выручки на объем отпуска воды потребителям, снижение объемов отпуска воды представляет собой дополнительный вклад в прирост тарифа. Немалую роль в снижении объемов потребления сыграл такой фактор, как установка приборов учета у потребителей. В отсутствие приборов учета объемы водопотребления определялись по нормативам, которые были зачастую завышенными. Приборное определение объемов воды, во-первых, показывает реальное значение потребления, во-вторых, стимулирует потребителей экономить, в-третьих, предотвращает расточительный и непроизводительный расход ресурса.

Повышение эффективности деятельности водоснабжающих организаций за счет снижения удельного расхода электроэнергии на подачу воды в сеть, снижения потерь воды, улучшения качества очистки воды требует инвестиционных затрат с прогнозируемыми сроками окупаемости. В условиях одновременного снижения объемов потребления и ограничения роста тарифов это невозможно без привлечения других источников финансирования. Основным инструментом государствен- 
ной политики, способным повлиять на состояние основных фондов в сфере водоснабжения, является Федеральная целевая программа «Чистая вода», предусмотренная на срок до 2024 г.

Таким образом, тарифное регулирование отрасли водоснабжения в Российской Федерации осуществляется в жестких рамках, что приводит к тому, что при формировании базового уровня затрат водоснабжающих организаций органы регулирования тарифов стремятся уменьшать расходы по каждой из формируемых статей затрат. Это приводит к убыточности деятельности водоснабжения у значительной части предприятий.

Решение этой проблемы возможно при распространении в практике регулирования тарифов метода сравнения аналогов на всю деятельность, связанную с водоснабжением, а не только на малые объемы транспортировки воды (Агафонов, Кузнецов, 2020а, 2020б).

Трудозатраты на сравнение и обработку данных для применения эталонного метода вполне сравнимы с трудозатратами работников органов государственного тарифного регулирования на проведение постатейного анализа планируемых затрат в тарифных заявках. Кроме того, постатейное установление затрат приводит к необходимости постатейного же контроля за соответствием фактических расходов утвержденным расходам, выявлению экономически необоснованных расходов и корректировке тарифной выручки в последующие периоды регулирования.

По мнению авторов статьи, применение метода сравнения аналогов (эталонных затрат) позволит повышать экономическую әффективность деятельности именно тех регулируемых организаций, у которых она находится на низком уровне, в отличие от метода индексации, где предусматривается повышение экономической эффективности всех организаций, даже тех, у которых она находится на достаточно высоком уровне. Кроме того, внедрение этого метода должно снизить трудозатраты регулируемых организаций на подготовку тарифных заявок и сузить возможность принятия регулирующими органами необъективных решений.

\section{2. Исходные данные и методы исследования}

Для попытки применить метод эталонных затрат к регулированию тарифов в сфере водоснабжения авторы исследования сформировали базу показателей деятельности 48 водоснабжающих предприятий в различных регионах Российской Федерации ${ }^{1}$. Для сравнения аналогов исследовалась фактическая себестоимость водоснабжения.

Авторы исследовали взаимную корреляцию технологических и производственных показателей для исключения автокорреляции. Для выявления связи себестоимости с технологическими и производственными показателями также применялись методы пошаговой регрессии. Для построения функции зависимости себестоимости от

\footnotetext{
${ }^{1}$ Раскрытие информации. Федеральная антимонопольная служба Российской Федерации. (http://ri.eias.ru/
} Map.aspx). 
влияющих факторов методом наименьших квадратов была проведена линеаризация взаимосвязей между себестоимостью и каждым из влияющих факторов.

Методология определения эталонных значений на основе бенчмаркинга была подробно рассмотрена в научно-исследовательской работе «Разработка методологии стимулирующего тарифного регулирования распределительных электросетевых компаний на основе бенчмаркингового исследования удельной стоимости обслуживания», выполненной РАНХиГС в 2017 г. (Suyunchev, Repetuk, Tregubova, 2017). В этой работе был предложен метод определения эталонных расходов на основе функции аппроксимации расходов с применением целевых коэффициентов эффективности. Этот метод предусматривает расчет относительного отклонения фактических расходов от аппроксимированных значений для каждой компании, а также сортировку компаний в порядке возрастания относительных отклонений (шкала эффективности) и определение минимального относительного отклонения $\min (\Delta \Pi \mathrm{P})$. Коэффициент эффективности для каждой компании на основании шкалы эффективности рассчитывается по формуле

$$
\mathrm{K}_{i}=\exp \left(-\Delta \Phi \mathrm{P}_{m i}\right),
$$

где $\mathrm{K}_{i}-$ коэффициент әффективности у компании $i$; $\Delta$ Р $_{m i}-$ перемасштабированное относительное отклонение фактических расходов от аппроксимированного значения у компании $i$ определяется по формуле

$$
\Delta \Phi \mathrm{P}_{m i}=\Delta \Phi \mathrm{P}_{i}-\min (\Delta \Phi \mathrm{P}),
$$

$\Delta \Phi \mathrm{P}_{i}-$ относительное отклонение фактических расходов от аппроксимированного значения по компании $i, \min (\Delta \Phi \mathrm{P})$ - минимальное значение относительного отклонения фактических расходов от аппроксимированных значений в рассматриваемой выборке компаний.

Целевой показатель эффективности на период регулирования устанавливается регулирующим органом. В компаниях, у которых коэффициент эффективности выше целевого значения, эталонные расходы принимаются на уровне фактических расходов соответствующего периода. В компаниях, у которых значение коэффициента эффективности ниже целевого, эталонные расходы принимаются исходя из аппроксимированных значений, скорректированных с учетом относительного отклонения, соответствующего целевому уровню эффективности

$$
\ni \mathrm{P}_{i}=\min \left(\Phi \mathrm{P}_{i} \mid \mathrm{AP}_{i}\left(1-\ln \left(\mathrm{K}_{\text {эц }}\right)\right)+\min (\Delta \Phi \mathrm{P})\right),
$$

где $Ф \mathrm{P}_{i}-$ фактические расходы у компании $i$; $\mathrm{AP}_{i}-$ аппроксимированные расходы у компании $i ; \ln \left(\kappa_{\text {эц }}\right)$ - логарифм значения целевого коэффициента эффективности.

Суть метода целевых коэффициентов эффективности: при регулировании тарифов установить допустимый процент превышения аппроксимированных расходов, рассчитать значения аппроксимированных расходов, увеличенные на этот допустимый процент, и сравнить их с фактическими значениями. Для предприятия, у которого 
размеры фактических расходов ниже значения увеличенных аппроксимированных расходов, в качестве эталона принимается величина фактических расходов. Для предприятия, у которого размеры фактических расходов выше значения увеличенных аппроксимированных расходов, в качестве эталона принимается значение увеличенных аппроксимированных расходов.

\section{3. Результаты исследований}

В практике тарифного регулятора OFWAT (Великобритания) с 2015 г. используется эконометрическая модель полных расходов операторов оптового водоснабжения и водоотведения, а до 2015 г. применялась модель операционных расходов. При формировании моделей из состава данных исключаются местные налоги, единовременные и нетипичные расходы (OFWAT, 2014).

Анализ деятельности ${ }^{2} 48$ российских водоснабжающих компаний (перечень приведен в Приложении, п. А) за 2018-2019 гг. показал, что модель зависимости полной себестоимости от влияющих факторов не является устойчивой. Очевидным объяснением этому служат специфичность ресурсных расходов, таких как затраты на покупку воды у сторонних организаций, расходы на приобретение химических реагентов, которые зависят от качества исходной воды и от применяемых технологий очистки. Удельный расход электроэнергии на подачу воды в сеть обусловлен силой напора, создаваемого в сети, составом и уровнем загрузки оборудования станций водоочистки, а цена электроэнергии сильно различается не только по регионам, но и в пределах одного региона - в зависимости от уровня напряжения в месте подключения. Для расчета расходов по ресурсным статьям целесообразно применить либо затратный, либо инженерный методы расчета.

Также затратным методом может быть рассчитан размер амортизационных отчислений, который существенно различается в зависимости от возраста и состава производственных фондов, проведения (непроведения) их переоценки.

У некоторых водоснабжающих организаций в составе расходов присутствует арендная плата. Ее размер для регулируемых организаций ограничен суммарным размером амортизационных отчислений и налога на имущество у арендодателя. Эту статью затрат также следует исключить из себестоимости при построении экономической модели.

Оставшуюся после исключения вышеперечисленных затрат компоненту себестоимости авторы статьи назвали безресурсной составляющей себестоимости (БРСС), ввиду того что в ней из себестоимости исключены стоимость приобретения материальных ресурсов и аналогичная ресурсу стоимость права владения производственными фондами (в виде амортизации и арендной платы).

В качестве переменных, влияющих на размер БРСС, по результатам корреляционно-регрессионного анализа были приняты:

${ }^{2}$ Раскрытие информации. Федеральная антимонопольная служба Российской Федерации (http://ri.eias.ru/ Map.aspx). 
- количество водопроводных насосных станций (ед.),

- протяженность водопроводных сетей (км),

- объем воды, пропущенной через очистные сооружения (тыс. $\mathbf{M}^{3} /$ год).

Зависимость БРСС от каждой из влияющих переменных имеет нелинейный характер (рис. 2-4).
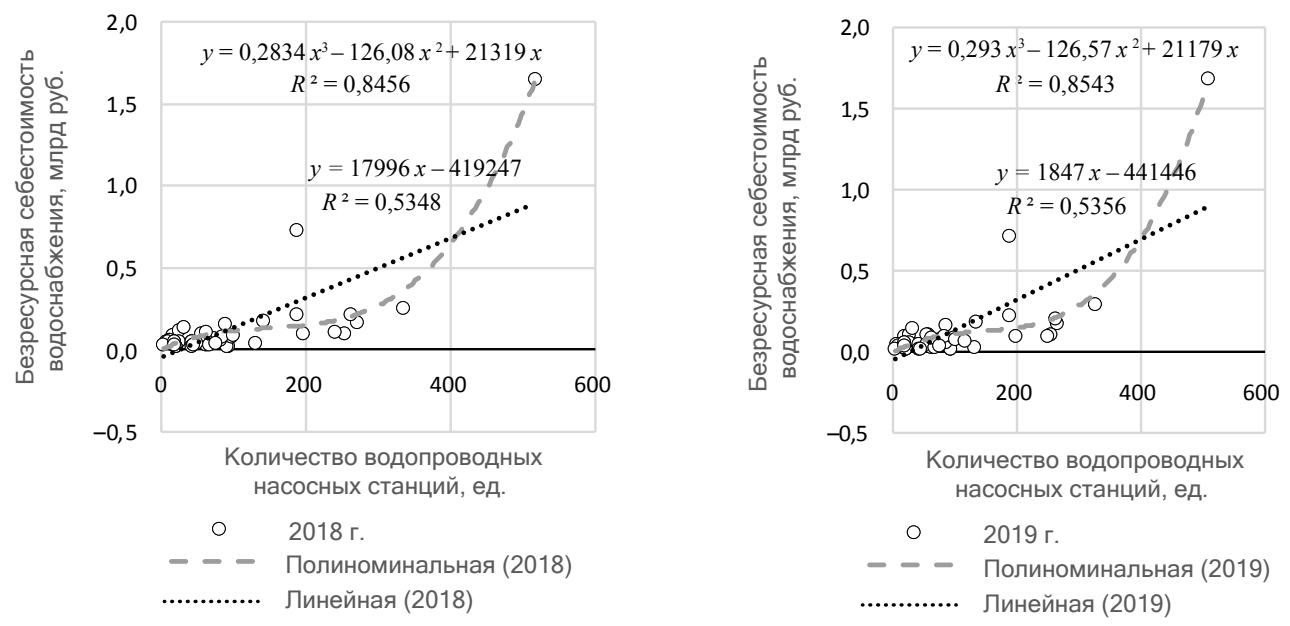

Puc. 2

Зависимость безресурсной себестоимости от числа водопроводных насосных станиий

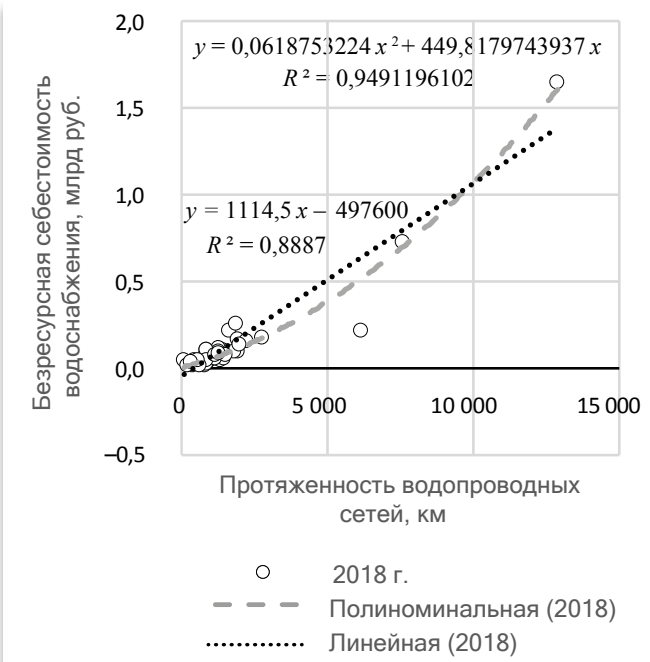

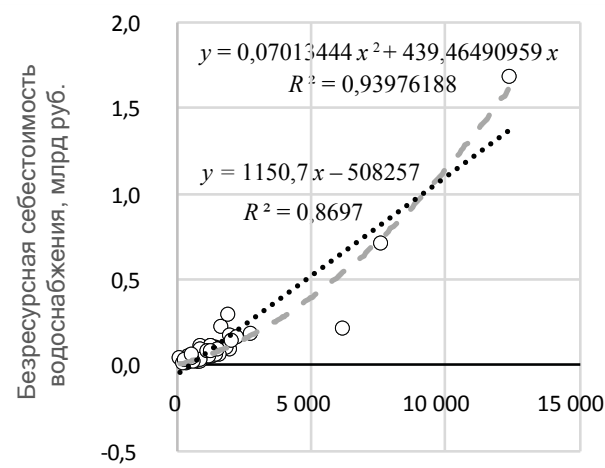

Протяженность водопроводных сетей, км

○ 2019

- - - Полиноминальная (2019)

............. Линейная (2019)

Puc. 3

Зависимость безресурсной себестоимости от протяженности водопроводных сетей

Источник: расчеты авторов по данным http:/ / ri.eias.ru/Map.aspx 


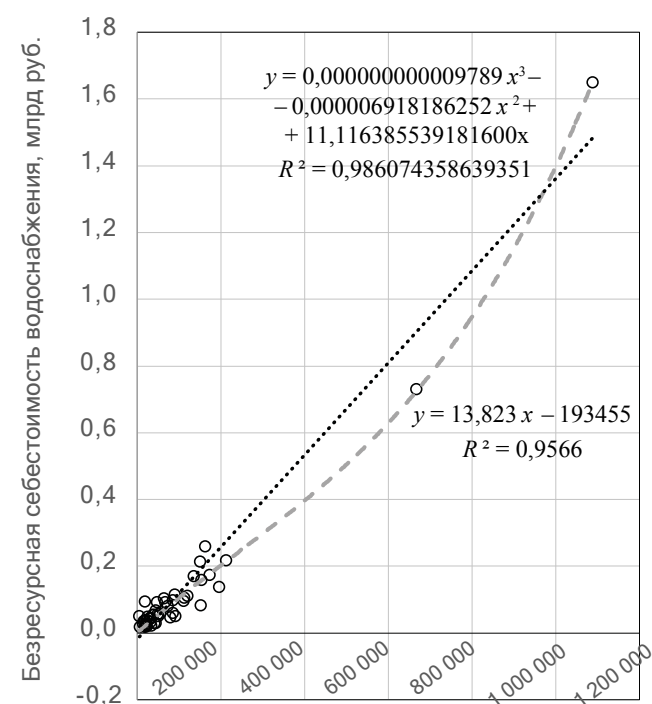

Объем воды, пропущенной через очистные сооружения, тыс.м³/год

○ 2018

- - - Полиноминальная (2018)

. Линейная (2018)

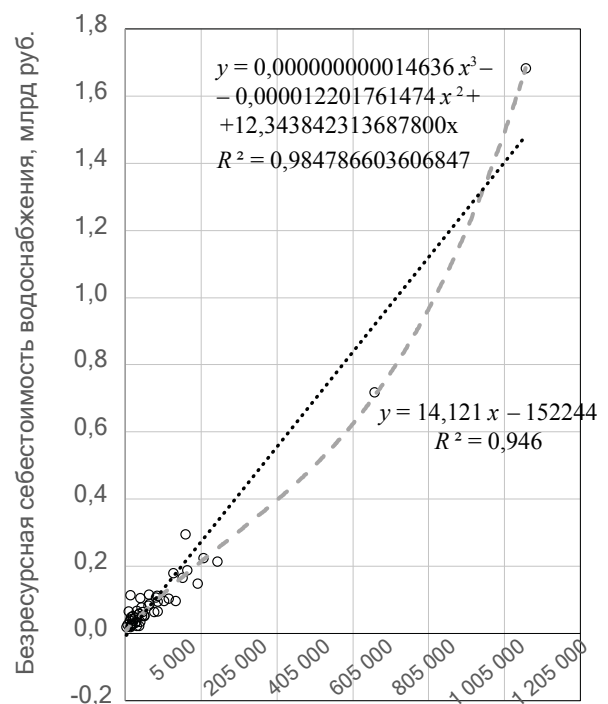

Объем воды, пропущенной через очистные сооружения, тыс.м³/год

- 2019

- - - Полиноминальная (2019) Линейная (2019)

Puc. 4

Зависимость безресурсной себестоимости от обвема очищенной водъ

Источник: расчеты авторов по данным http:/ / ri.eias.ru/Map.aspx

Наибольшее по объемам производства предприятие ОАО «Мосводоканал» - демонстрирует, что с ростом масштаба не происходит снижения удельных затрат (вопреки теории естественных монополий). Авторы исследования не стали исключать ОАО «Мосводоканал» из выборки, чтобы попытаться создать единую модель безресурсной составляющей себестоимости.

Для построения трехфакторной аппроксимации величины безресурсной составляющей себестоимости от влияющих переменных была проведена линеаризация ее зависимости от каждой из переменных с помощью полиномиальных уравнений (см. рис. 2-4). Статистические показатели трехфакторной регрессии приведены в табл. 2.

Критическое значения t-статистики для доверительной вероятности 95\% и 3-факторной модели для выборки по 46 организациям (43 степени свободы) по таблице значений критерия Стьюдента равен примерно 2,01. Поэтому из полученных коэффициентов 3-факторной линейной регрессии является статистически незначимым только второй коэффициент в выборке 2019 г. 


\section{таблица 2}

Показатели линейной регрессии безресурсной себестоимости водоснабжения линеаризованных переменных по данным 2018-2019 гг.

\begin{tabular}{|c|c|c|c|}
\hline Параметр & $\begin{array}{l}\text { Коэффи- } \\
\text { циент } \\
\text { регрессии }\end{array}$ & $\begin{array}{c}\text { Стандартная } \\
\text { ошибка }\end{array}$ & t-статистика \\
\hline \multicolumn{4}{|c|}{2018 г. } \\
\hline$x_{1}=0,2834 \mathrm{~K}^{3}-126,08 \mathrm{~K}^{2}+21319 \mathrm{~K}$ & 0,09144 & 0,04194 & 2,18049 \\
\hline$x_{2}=0,061875 \Pi^{2}+449,818 \Pi$ & 0,20315 & 0,06514 & 3,11847 \\
\hline$x_{3}=0,9789 \times 10^{-11} \mathbf{Y}^{3}-0,69182 \times 10^{-5} \mathbf{Y}^{2}+11,1164 \mathrm{\Psi}$ & 0,72536 & 0,06918 & 10,48567 \\
\hline \multicolumn{4}{|c|}{2019 г. } \\
\hline$x_{1}=0,293 \mathrm{~K}^{3}-126,57 \mathrm{~K}^{2}+21179 \mathrm{~K}$ & 0,10377 & 0,04681 & 2,2168 \\
\hline$x_{2}=0,07013 \Pi^{2}+439,464 \Pi$ & 0,03157 & 0,08112 & 0,38915 \\
\hline$x_{3}=1,4636 \times 10^{-11} \mathbf{Y}^{3}-1,2202 \times 10^{-5} \times \mathrm{Y}^{2}+12,344 \times \mathrm{\Psi}$ & 0,87805 & 0,09294 & 9,44702 \\
\hline
\end{tabular}

Примечание. К - число водопроводных насосных станций, ед.; П - протяженность водопроводных сетей, км; Ч - объем очищенной воды, тыс. м².

Источник: расчеты авторов по данным http:/ / ri.eias.ru/Map.aspx

$$
\begin{aligned}
& \text { Уравнения аппроксимации получились довольно громоздкими: } \\
& \mathrm{C}_{2018}=0,0257 \mathrm{~K}^{3}-11,3746 \mathrm{~K}^{2}+1925,25 \mathrm{~K}+0,0126 \Pi^{2}+90,8823 \Pi+ \\
& +0,7101 \times 10^{-} 11 \times \mathrm{\Psi}^{3}+0,000005018 \mathrm{\Psi}^{2}+8,0634 \mathrm{\Psi} \text {; } \\
& \mathrm{C}_{2019}=0,0302 \mathrm{~K}^{3}-12,9603 \mathrm{~K}^{2}+2170,87 \mathrm{~K}+0,0022145 \Pi^{2+13,8661 \Pi+} \\
& +1,285 \times 10^{-11} \times \mathrm{\Psi}^{3}+0,000010714 \mathrm{Ч}^{2}+10,8385 \Psi,
\end{aligned}
$$

где $C_{2018}$ и $C_{2019}-$ БРСС водоснабжения в 2018 и 2019 г. соответственно. Погрешность аппроксимации составляет 29,5\% для модели 2018 г., 31,2\% - для модели 2019 г. В 2018 г. выше средней погрешность аппроксимации в сторону занижения затрат у ГОУП «Мурманскводоканал» $(38 \%)$; ООО «Красноярский жилищно-коммунальный комплекс» (62\%); АО «Водоканал» г. Якутск (86\%); Смоленское МУП «Горводоканал» (39\%), ОАО «Сыктывкарский Водоканал» (45\%). Выше средней погрешность аппроксимации в сторону завышения затрат у предприятий МУП «Водоканал» г. Иркутск (69\%); АО «Тамбовские коммунальные системы» (118\%); АО «Водоканал» г. Чебоксары (56\%); АО «Тулагорводоканал» (80\%); МП г. Пскова «Горводоканал» (45\%); ООО «Тверь Водоканал» (56\%); МУП «Брянскгорводоканал» (55\%); УМУП «Ульяновскводоканал» $(56 \%)$; ООО «Концессии водоснабжения Саратов» (72\%). Эти же предприятия лидируют и по погрешности аппроксимации 2019 г.

Авторы исследовали в качестве возможных факторов улучшения модели размер средней заработной платы в регионе и размер средней заработной платы в регионе по виду деятельности «Забор, очистка и распределение воды» 3 , однако это не дало положительного результата.

3 https://www.audit-it.ru/inform/zarplata/index_old.php 
Для проверки устойчивости модели авторы применили формулу (4), рассчитанную на основании данных 2018 г., для расчета БРСС исходя из величин влияющих переменных по данным 2019 г. Получившиеся значения отличаются от значений, полученных по формуле аппроксимации (2), в меньшую сторону в пределах 2,8-8,6\% (медианное отличие составило $6,3 \%$ ). Единственное исключение - значение аппроксимации для ГУП «Водоканал Санкт-Петербурга» по формуле (1) оказалось выше, чем по формуле (2), но всего на 1,1\%. Из этого можно сделать следующие выводы:

- формула (5) отражает увеличение аппроксимированной БРСС в 2019 г. по сравнению с 2018 г. для большинства предприятий на $6,3 \%$;

- устойчивость выявленной зависимости позволяет использовать аппроксимационную модель для прогноза затрат на последующие периоды с применением прогнозных индексов инфляции.

Сравнение фактических величин БРСС за 2019 г. с аппроксимированными по формулам (4) и (5) приведено на рис. 5-7 в логарифмических координатах.

Графики на рис. 5-7 показывают, что формулы аппроксимации (4) и (5) хуже согласуются с фактическими данными в области малых значений объема очищенной воды (до 15 тыс. м³ / год), протяженности сетей ниже 418 км и единичного числа насосных станций (2 ед.). Для предприятий с такими показателями следует сформировать отдельную базу данных для проведения аппроксимационных расчетов.

На рис. 8 представлены результаты расчета эталонных затрат, выполненного авторами методом целевого коэффициента эффективности с использованием формулы аппроксимации (5). При целевом коэффициенте эффективности, равном среднему значению эффектив-

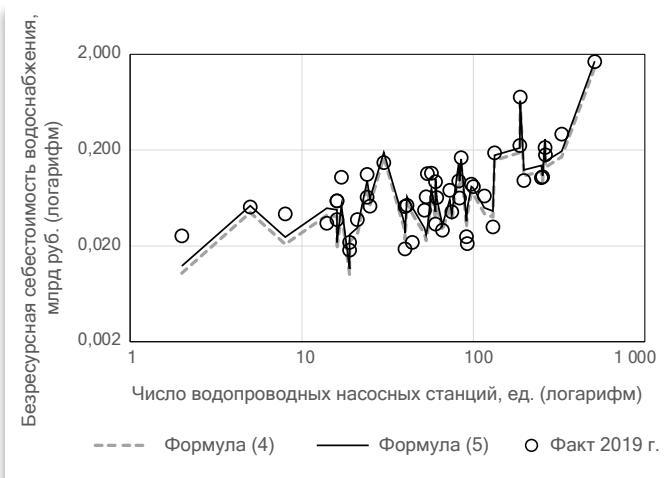

Pис. 5

Зависимость БРСС от числа насосных станиий по данным 2019 г. и графики значений

по формулам аппроксимачии

Источник: расчеты авторов по данным http:/ /ri.eias.ru/Map.aspx

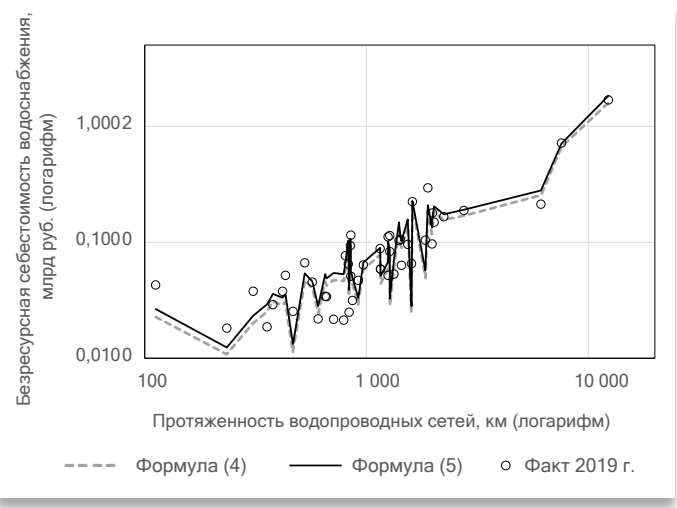

Puc. 6

Зависимость БРСС от протяженности водопроводных сетей по данным 2019 г. и графики значений по формулам аппроксимачии

Источник: расчеты авторов по данным http:/ / ri.eias.ru/Map.aspx 


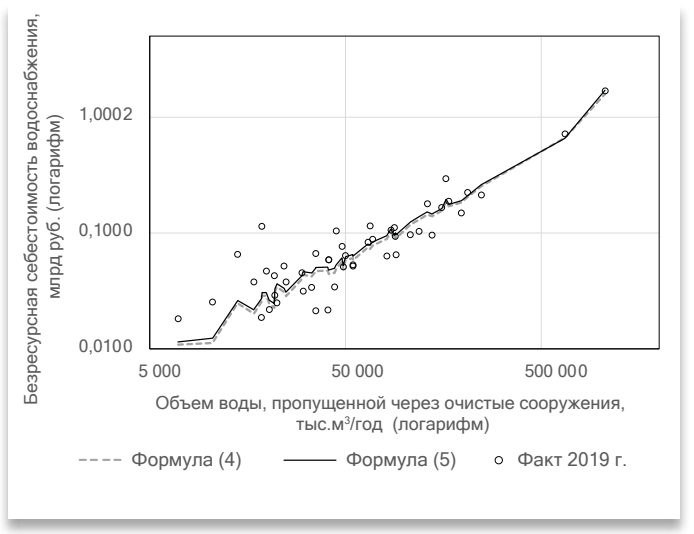

Puc. 7

Зависимость БРСС от объема очищенной водъ по данным 2019 г. и графики значений по формулам аппроксимачии

Источник: расчеты авторов по данным http://ri.eias.ru/Map.aspx

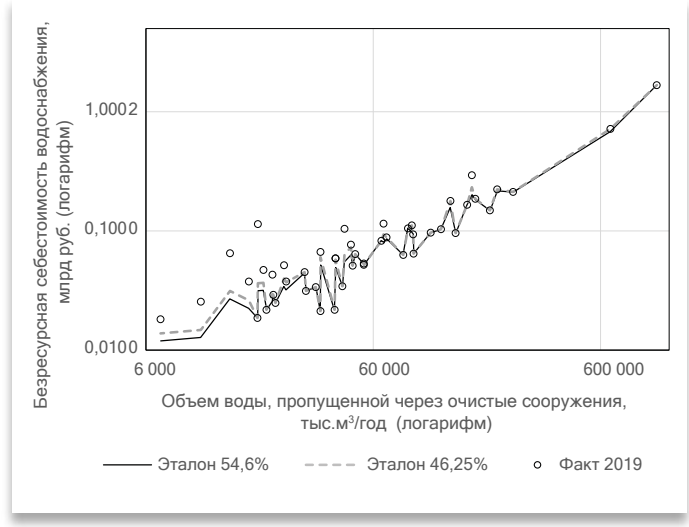

Puc. 8

Зависимость эталонной БРСС от объема очищенной воды по данным 2019 г. для иелевой эффективности 54,6 и 46,25\%.

Источник:данные для фактических данных взяты c http:/ /ri.eias.ru/Map.aspx, для эталонных - расчеты авторов.

ности $54,6 \%$, для предприятий, имеющих коэффициент әффективности ниже целевого, эталонная БРСС всего на 3,4\% выше аппроксимированного значения. Фактическая БРСС более чем на $20 \%$ превышает эталонную БРСС у 12 предприятий из 48.

Чтобы сгладить воздействие перехода на эталонные затраты, можно выбрать более низкое значение целевого коэффициента эффективности. Если принять допустимое завышение эталонной БРСС на $20 \%$ (при этом целевой коэффициент эффективности равен 46,25\%), то число предприятий, у которых разница между фактической и эталонной величинами БРСС превышает 20\%, сокращается до девяти.

В российской практике (на примере перехода на эталонное регулирование гарантирующих поставщиков электроэнергии) сглаживание перехода на эталонные затраты осуществляется распределением изменения затрат на период до нескольких лет. (Правда, у гарантирующих поставщиков электроэнергии при переходе на эталонный метод регулирования затраты не снизились, а возросли.)

\section{4. Обсуждение результатов}

Авторы рассчитали функцию аппроксимации безресурсной составляющей себестоимости водоснабжения от трех влияющих факторов по фактическим показателям 48 водоснабжающих организаций. Причиной высокой (около 30\%) погрешности аппроксимации могут служить как неучтенные факторы и особенности деятельности водоснабжающих организаций, так и воздействие тарифного регулирования (при заниженных тарифах вынужденная экономия расходов приводит к заниженной фактической себестоимости). 
Для обеспечения равных условий деятельности более справедливой была бы линейная зависимость БРСС от влияющих факторов, однако для собранной базы данных точность полиномиальной аппроксимации оказалась выше.

Сами величины БРСС требуют коррекции. Для того чтобы сделать сравнимыми стоимость использования собственных производственных активов (амортизационные отчисления) и арендованных производственных активов, следует учесть и вычесть из безресурсной составляющей себестоимости налог на имущество по собственным активам. Также ресурсной статьей затрат для водоснабжающей организации является стоимость используемой непокупной воды, которая выражается в форме платы за воду, или водного налога. Так как для водоснабжающих организаций это один из важнейших ресурсов, он должен быть представлен в перечне информации, подлежащей раскрытию. Возможно, что при уточнении величин БРСС точность аппроксимации удастся повысить.

Более корректным фактором, определяющим БРСС у водоснабжающей организации, является не объем очищенной воды, а установленная производительность станций водоподготовки. Аналогично, наряду с числом насосных станций влияющим фактором может быть их суммарная производительность.

Также в построении модели нелишним будет показатель «число абонентов», который используется как для нормирования численности работников водопроводно-канализационного хозяйства в РФ, так и в практике бенчмаркинга в Великобритании и Австралии. Однако все вышеназванные показатели отсутствуют на портале публикации сведений, подлежащих свободному доступу (см. сайт Федеральной антимонопольной службы Российской Федерации http:/ / ri.eias.ru/Map.aspx).

Явное увеличение погрешности аппроксимации в области малых значений влияющих параметров свидетельствует о необходимости дополнительного сбора данных о показателях деятельности водоснабжающих предприятий малого масштаба для дальнейших эконометрических исследований.

\section{5. Выводы}

По результатам проведенного исследования авторы пришли к выводу, что в Российской Федерации применяются элементы компромиссного регулирования тарифов в части ограничения роста тарифов на услуги водоснабжения с учетом доходов населения. В этих условиях утверждаемая необходимая валовая выручка водоснабжающих организаций зачастую подвергается необоснованному снижению, что впоследствии приводит к убыткам, особенно с учетом тенденции уменьшения объемов водопотребления.

Процессы тарифного регулирования требуют значительных трудозатрат как у региональных органов тарифного регулирования, 
так и у регулируемых организаций, а сам процесс регулирования подвергается критике в связи с недостаточной информационной прозрачностью. Одним из способов устранения этих недостатков является более широкое внедрение эталонного метода регулирования, который в Российской Федерации ограниченно применяется только для тарифов на транспортировку воды в небольших объемах.

Метод сравнения аналогов неприменим к размерам затрат на материальные и энергетические ресурсы, амортизации и арендной платы, так как они существенно зависят от специфических условий деятельности водоснабжающих организаций. Однако часть себестоимости, из которой эти затраты исключены (БРСС), может быть определена исходя из эталона, рассчитанного методом целевой эффективности на основе функции аппроксимации БРСС от влияющих факторов, как это продемонстрировано в данной статье, с применением прогнозных индексов инфляции для последующих периодов регулирования.

Однако для полноценного сравнительного анализа предприятий водоснабжения необходимо расширить состав системных данных о деятельности предприятий водоснабжения, таких как число абонентов; производительность насосных станций; число и производительность станций водоподготовки. Также в составе себестоимости следует детализировать размеры налога на имущество, платы за воду в бюджет и водного налога.

Применение метода сравнения аналогов должно повысить прозрачность и сделать проще тарифное регулирование, а также создать стимулы для повышения экономической эффективности деятельности предприятий. 


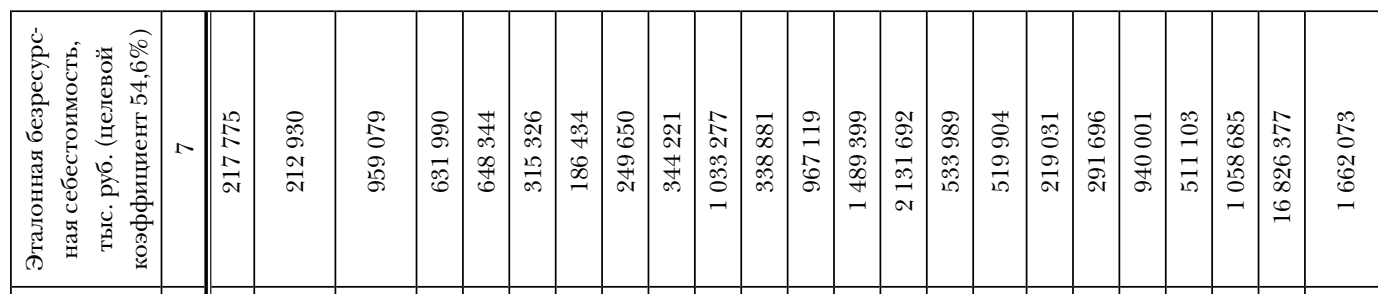

悹产。

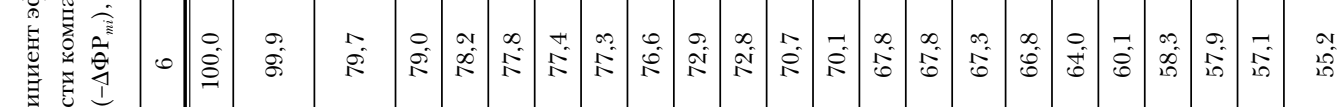

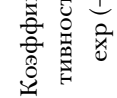

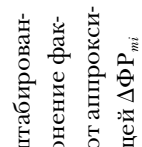

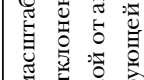

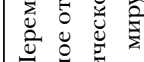

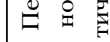

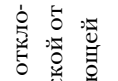

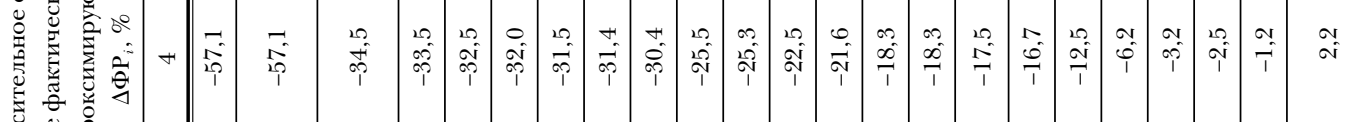

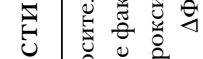

空

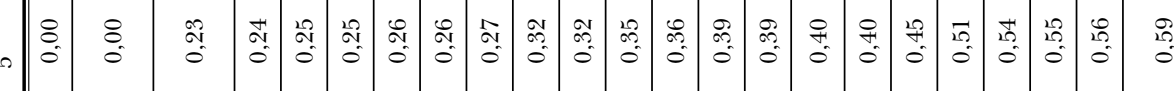

ڤั山

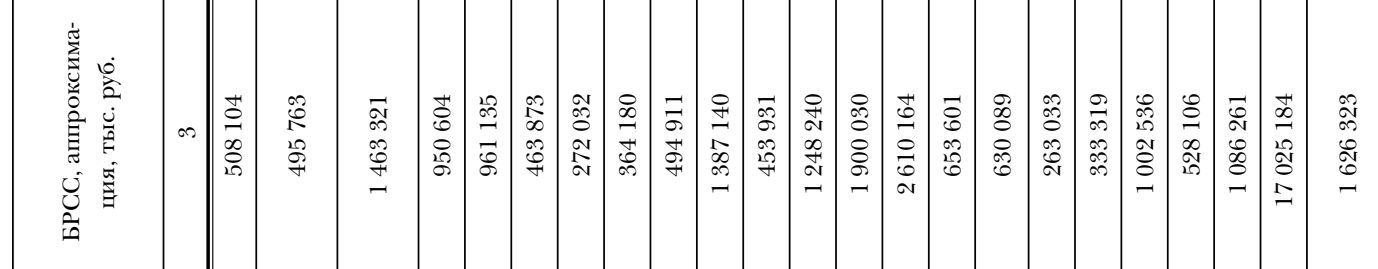

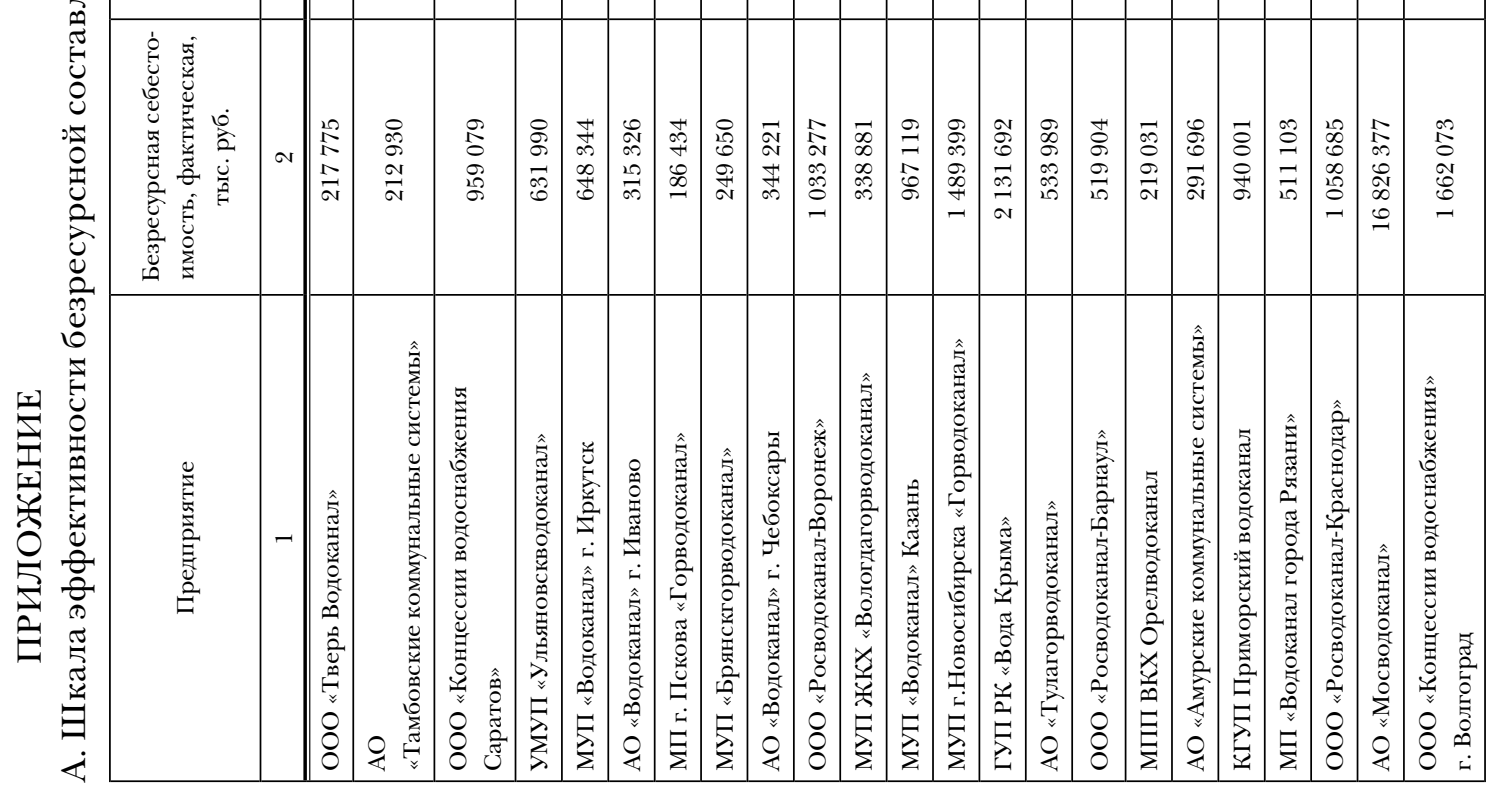




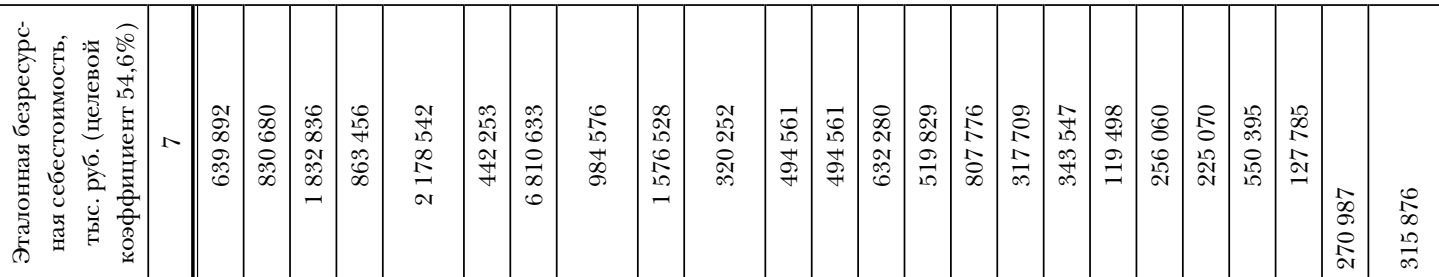

离泀

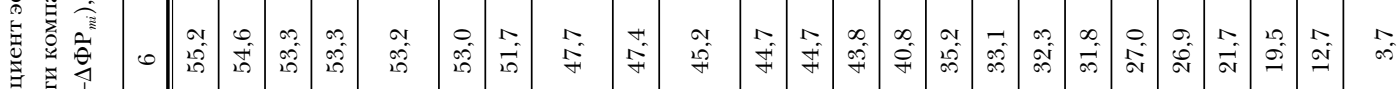

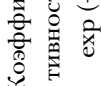

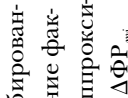

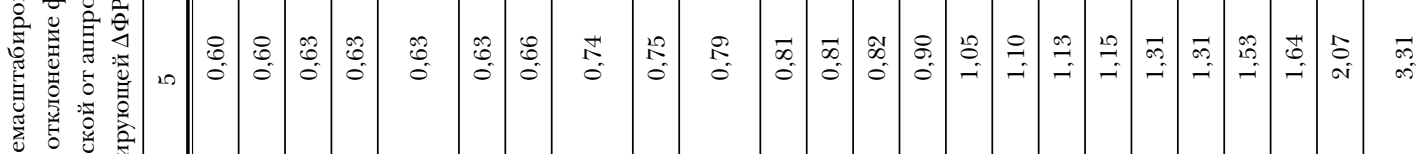

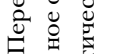

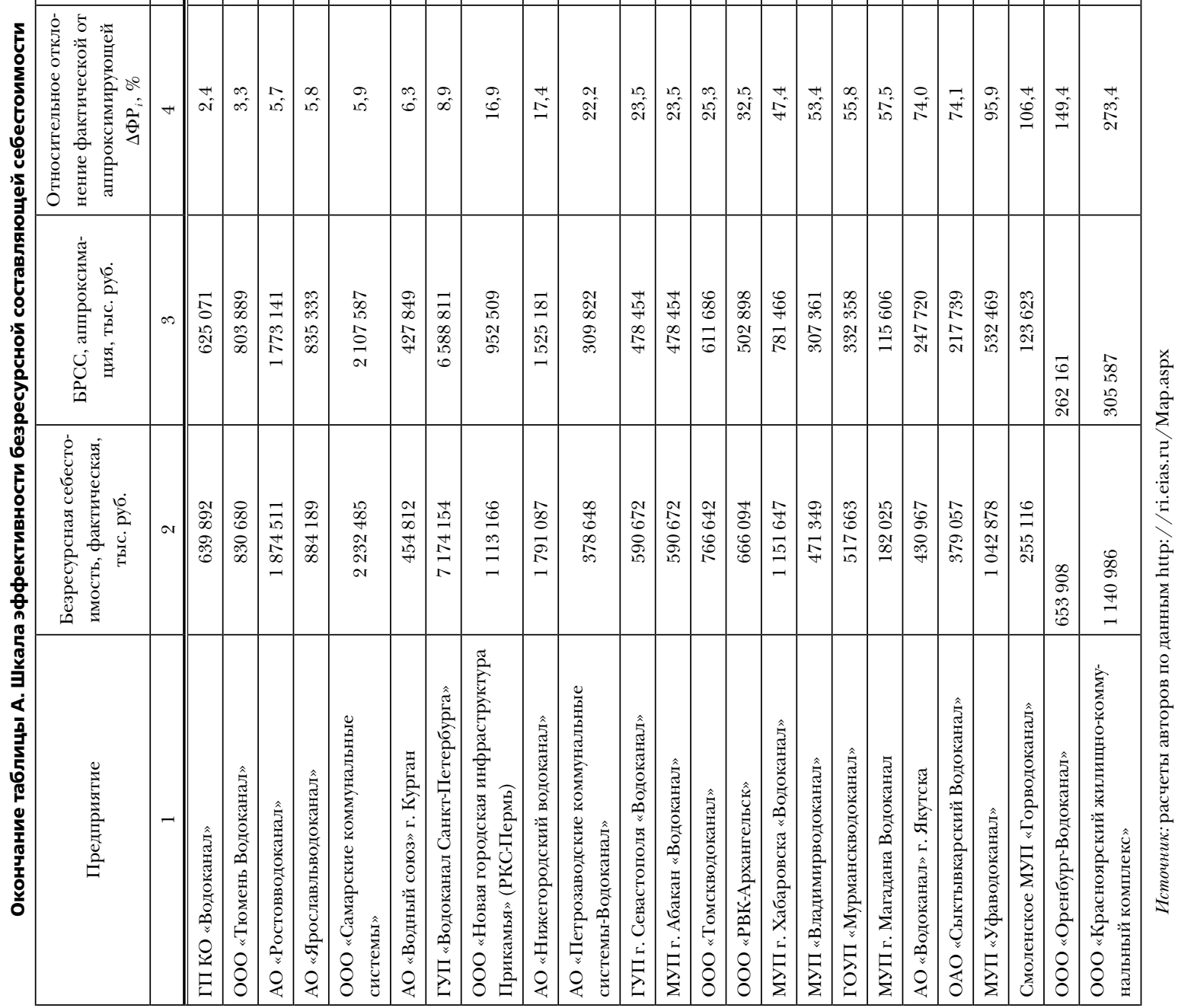




\section{ЛИТЕРАТУРА / REFERENCES}

Агафонов Д.В., Кузнецов В.В. (2020а). Метод сравнения аналогов в российском водоснабжении: решение проблем или нет // Вопросы управления. № 3 (64). C. 114-124.=[Agafonov D.V., Kuznetsov V.V. (2020a). Method of comparison of analogs in the Russian water supply: solution of problems or not. Management Issues, 3 (64), 114-124 (in Russian).]

Агафонов Д.В., Кузнецов В.В. (2020б). Особенности внедрения эталонного ценообразования в отношении российских предприятий водоснабжения с учетом зарубежной практики тарифного регулирования // Вестник Московского университета имени С. Ю. Витте. Серия 1. Экономика и управление. № 2 (33). C. 64-72. [Agafonov D.V., Kuznetsov V.V. (2020b). Specifics of introducing reference pricing of water supply companies by taking into account foreign practice of tariff regulation. Moscow Witte University Bulletin, 2 (33), 64-72 (in Russian).]

Башмаков И.А. (2003). Тарифы на жилищно-коммунальные услуги. Есть ли предел роста? / / Энергосбережение. № 6. C. 20-26. [Bashmakov I.A. (2003). The utility service tariffs. Is there a limit to growth? Energosberezhenie, 6, 20-26 (in Russian).]

Башмаков И.А. (2004). Способность и готовность населения оплачивать жилищно-коммунальные услуги // Вопросы экономики. № 4. С. 136-150. [Bashmakov I.A. (2004). Readiness and willingness of population to pay for housing and communal services. Voprosy Ekonomiki, 4, 136-150 (in Russian).]

Гембик Ю.С., Городкова С.А. (2018). Проблемы практического применения законодательных методов регулирования тарифов в сфере водоснабжения и водоотведения // Вестник Томского государственного университета. Экономика. № 41. C. 281-291. [Gembik Y.S., Gorodkova S.A. (2018). Problems of practical application the legal methods of regulation tariffs in water supply and sanitation. Tomsk State University Journal of Economics, 41, 281-291 (in Russian).]

Довлатова Е.В., Эпштейн А.Д. (2019). Новый метод регулирования тарифов: от бенчмаркинга к эталонированию статей затрат // Наилучшие достуnные технологии водоснабжения и водоотведения. № 2. C. 2-5. [Dovlatova E.V., Epstein A.D. (2019). New method of tariff regulation: till benchmarking to yardsticks of cost items. Best Available Technologies (NDT) for Water and Sanitation, 2, 2-5 (in Russian).]

Кракашова О.А. (2010). Государственное регулирование как способ формирования «компромиссной» эффективности жилищно-коммунального комплекса. В сб.: «Материалы Всероссийской научно-практической конференции "Инновационная экономика: проблемы и перспективы развития в Северо-Западном федеральном округе”». С. 182-186. [Krakashova O.A. (2010). The government regulation as a way to create a "compromise" efficiency of the utility complex. Materials of the All-Russian scientific and practical conference "The Innovative economy: Problems and development prospects in the Northwestern Federal District”, 182-186 (in Russian).]

Матвиенко Д.А., Курносова В.Ф., Курносова Н.С., Резников В.В. (2015). Моде- 
лирование компромиссных тарифов на жилищно-коммунальные услуги в Российской Федерации. В сб.: «Современные направления теоретических и прикладных исследований». [Matvienko D.A., Kurnosova V.F., Kurnosova N.S., Reznikov V.V. (2015). The Modeling of the utility services' compromise tariffs in the Russian Federation. In: Modern trends of theoretical and applied researches. 13 p. (in Russian).]

Сорокин М.А. (2015). Эволюция методов тарифообразования на услуги естественных монополий / / Проблемы учета и финансов. № 4 (20). С. 63-68. [Sorokin M.A. (2015). The evolution of methodologies of natural monopoly services rates formation. Problems of Accounting and Finance, 4 (20), 63-68 (in Russian).]

Суюнчев M.M., Репетюк C.B., Трегубова E.A. (2017). Разработка методологии стимулирующего тарифного регулирования распределительных электросетевых компаний на основе бенчмаркингового исследования удельной стоимости обслуживания. М.: РАНХиГС. [Suyunchev M.M., Repetuk S.V., Tregubova E.A. (2017). The development of incentive regulation methodology, based on benchmarking of distribution electricity networks maintenance unit costs. Moscow: RANEPA (in Russian).]

Akimov A., Simshauser P. (2018). Performance measurement in Australian water utilities: Current state and future directions. Australian Journal of Public Administration, 79 (1), 111- 42 .

Berg S.V. (2010). Water utility benchmarking: measurement, methodologies, and performance incentives. London: IWA Publishing.

Kenton W. (2018). Rate of Return Regulation. Investopedia. Available at: https: / /www. investopedia.com/terms/r/rate-of-return-regulation.asp

Mayer C., Vickers J. (1996). Profit-Sharing Regulation: An Economic Appraisal. Fiscal Studies, 2 (17), 83-101.

OFWAT (2014). Draft price control determination notice: technical appendix. OFWAT. Available at: https://www.ofwat.gov.uk/publication/draft-pricecontrol-determination-notice-technical-appendix /

Поступила в редакиию 07.12.2020

Received 07.12.2020 


\section{O.V. Temnaya}

Natural monopoly economies Institute, Russian Presidential Academy of National Economy and Public Administration, Moscow, Russia

D.V. Agafonov

Natural monopoly economies Institute, Russian Presidential Academy of National Economy and Public Administration, Moscow, Russia

\section{O.O. Mozgovaya}

Natural monopoly economies Institute, Russian Presidential Academy of National Economy and Public Administration, Moscow, Russia

\section{Incentive based regulation of water supply under tariffs limitation}

Abstract. The article browses methods of natural monopolies tariff regulation, applied in Russian Federation and foreign countries for the case of water supply. Three principles for natural monopolies tariff regulation are identified: compromise, compensatory, and Incentive based regulation. One of the Incentive based regulation methods - Yardstick Cost Method - has an advantage of regulated entities labor saving within the tariff protection. The other benefit of the method is the feasibility to grade providers from most to least economic performance and to regulate the economic performance improvement for ineffective providers specifically. Benchmarking of publicly available water supply costs data turned up that the costs of physical resources, amortization and rentals depend on specific conditions of enterprise. Therefore, the water supply costs exclusive of resource cost, amortization and rentals seems to be good as an outcome variable for Yardstick Cost Method. We calculated a formula of approximate functional relationship among three contributors and water supply costs exclusive of resource cost and amortization. The yardstick water supply costs were determined by target performance method applying the formula. Although the formula needs an upgrade, our calculations demonstrate a feasibility of Yardstick Cost Method practice for tariff regulation of Russian water suppliers.

Keywords: water supply, natural monopoly, tariff regulation, Incentive based regulation, benchmarking, Yardstick Costs, target performance.

JEL Classification: L16, L43, L51, L95.

DOI: $10.31737 / 2221-2264-2021-52-4-8$ 